\title{
Mechanical Performance Analysis of New Beam-Column Nodes of Assembled Portal Frames
}

\author{
Jie Cao and Dandan Mu* \\ Hebei Petroleum University of Technology, Chengde 067000, China
}

Received 1 September 2021; Accepted 29 November 2021

\begin{abstract}
Mechanical performance of beam-column end-plate connection nodes of portal frames can be influenced by different factors, including end plates, bolts, node domains, column flanges, and webs and stiffening ribs. To enhance the stress performance and bearing capacity of nodes, this study proposed a new type of beam-column node for assembled portal frames. Based on a single-floor-and-span plant, models of the beam-column nodes were established using the finite element software ANSYS. To simulate the actual structure of portal frames, a constraint along the Z-direction was added on the column top. Meanwhile, constraints along the X-, Y-, and Z-directions were added on the column bottom. A systematic study of its stress performance was carried out by a full loading system of "European Convention for Constructional Steelwork". In addition, a novel type of beam-column node was proposed on the basis of node stress performance analysis by changing the thickness of the end plates and the diameters of the bolts. Results demonstrate that thickness of the end plates displays an obvious influence on the bearing capacity of nodes. However, when an end plate is increased to $20 \mathrm{~mm}$, the influence tends to be weak. If only the bolt diameters change, then it enhances the rigidity of the beam-column connection and lowers the ductility and plastic rotation angles with slightly improved bearing capacity. After reaching the bolt diameter of $20 \mathrm{~mm}$, the diameter increase generates few effects on seismic performance. In addition, ways of end-plate placement exhibit a great influence on the bearing capacity of nodes. Vertical nodes of end plates have higher ultimate bearing capacity and rigidity, as well as worse seismic performance when compared with those of transverse ones. The stress performance of new nodes, namely IN1, IN2, and IN3, is significantly better than those of regular ones. These new nodes exert a good role in protecting node domains with high bearing capacity and good ductility, resulting in the effective weakening of node-domain stress concentration. This study provides an important reference for the design and application of portal frames.
\end{abstract}

Keywords: Portal frames; Beam-column nodes; Cyclic loading; Seismic performance

\section{Introduction}

Considering that the application of portal frames in architectural structure is currently increasingly, the appropriate node design of portal frames generates a direct influence on structural integrity and reliability, as well as construction cycles and costs [1]. Most nodes of portal frames are connected by end plates and mainly consist of end plates, bolts, node domains, column flange, and web, as well as stiffening ribs. Scholars carried out extensive studies and practices that are related to the effects of factors, including the specifications and dimensions of end plates and bolt specifications on node rigidity and ultimate bearing capacity. As beams and columns are connected by end plates, the deformation of an end plate can coordinate and relieve that of its beam and column, thereby avoiding their untimely collapse. As a result, the structural characteristics of end plates indicate their complexity [2].

In terms of the node design calculation of end plates, simplification and hypotheses of nodes cannot generally reflect the stress performance of light-steel nodes because of different design specifications, theories, and methods of steel structure in various countries. Considering that the nodes of

*E-mail address: mudandan7810@163.com

ISSN: 1791-2377 @ 2021 School of Science, IHU. All rights reserved.

doi:10.25103/jestr.145.22 portal frames are of anti-bending connection, the connection fasteners of end plates bear combined axial force and shear. End plates are either of rigid connection or semi-rigid connection in line with various M- $\theta$ curves, where node load transfer paths are quite complicated.

On this basis, considerable studies on beam-column nodes of portal frames have been conducted. These studies show that the seismic performance and node rigidity of beam-column nodes can be effectively improved by the proper thickening of end plates, and bearing capacity can be increased by strengthening node rigidity [3-4]. However, the force of end-plate nodes is complicated because of the influences of multiple factors, the highly nonlinear performance, and the dynamic rigidity with loading history. As a result, determining the rigidity and deformation of nodes still remains challenging. Therefore, improving node performance and rigidity remains a problem that demands prompt solution.

Therefore, the finite element software ANASYS was used to BASE models and various derived specimens for beam-column nodes of light-steel portal frames, where systematic study on stress performance was conducted to explore the effects end plate thickness, bolt diameters, and friction coefficients and the influence of the placement of end-plate on the bearing capacity and hysteretic performance of specimens. On this basis, new beam-column nodes of portal frames were established. 


\section{State of the art}

So far, scholars have performed numerous studies on the stress performance of portal frames, including the crosssection forms of beams and columns, column spacing, stability, corner nodes, connecting bolts, and end plates, as well as column-beam webs and flanges. Mojtabaei [5] investigated the structural performance of Cold - Formed Steel anti-bending connection and a joint-control failure mode that involved the local buckling of CFS component webs near bolts. An experimental verification finite-element model was established in ABAQUS with Python script, where material, geometric nonlinearity, and imperfection, as well as the bearing behavior of real bolts, were considered. However, no detailed study and analysis concern the overall stress performance and characteristics of nodes. Under static load, Skejic [6] conducted laboratory tests relating to steeltube welding knee joints with bolt connection units and numerical simulation with ANSYS to comprehend complex interaction among different connecting elements. However, due to limitations in laboratory equipment, only one rigid tie unit (circular tubes) was used, thereby requiring numerical simulations to extend the test results. M.Rezaiee-Pajand [7] primarily analyzed conical beams and columns by using two different methods and considered the substantial effects of coupling-tensile bending of this structure. In his analysis, the second-order effects and flexibility of connection were considered, whereas no force analysis of node domains was performed. Davies et al. [8] reduced the amount of steel structure in short shed-shaped structure of portal frames by skin effects of force, thereby leading to the massive evolution of shed-shaped structure, in which the dimensions significantly increased with taller and thinner frames, as well as increasing alternative coating systems. Besides, the sustained reaction in this condition was summarized while its improvement only involved algorithms. Based on reliability analysis with a dominant failure mode, Molkens [9] described the behavior of single-node portal frames in systems. In the condition of ultimate load with ultimate resistance of sections, a limited number of key sections could be applied to describe the failure mode of single-beam portal frames. He also studied the effects of building geometry (rise-span ratios) and load ratios on the reliability of single-beam portal frames. However, this study only involved the analysis of overall reliability without the detailed study of key nodes. By adding a mechanism in beam-column nodes, Andrea et al. [10] enhanced the seismic performance of typical portal frames, in which this mechanism could provide additional fixation and energy dissipation to accelerate construction. A mechanism added in the beam-column nodes could be used as a fuse to the concentration of seismic damage on a few sacrificed and replaceable components. Nevertheless, this work did not analyze the construction costs and practicability. Yurchenko et al. [11] presented a mathematical model for the parameter optimization of steel-latticework portal frames, where design variable vectors included the geometric parameters (nodal coordinates) and section dimensions of structure components, while its restraint system covered the bearing capacity restraints in all combinations of ultimate loads of all designed sections of the steel structure. On the principle of minimal weight and costs of manufacture and installation, a new optimal layout scheme was proposed for steellatticework portal frames. Meanwhile, a theoretical study was conducted without analyzing on overall stress performance of portal frames. Aria et al. [12] designed and explored all models through finite element software ABAQUS; evaluated the impacts of steel-bending dampers on energy dissipation, strength, and rigidity of portal frames; and conducted the seismic energy dissipation of the integral structure with steel-bending dampers. Furthermore, dampers with five different angles and eccentric distances were compared with one another. The seismic performance of the integral structure and performance of key parts, such as nodes, were analyzed. Sina et al. [13] conducted the static nonlinear analysis of rigid frames with OpenSees software, studied the influences of symmetric and asymmetric support, as well as carried out a comparative study of buckling-load response obtained in different support and geometry conditions without carrying out performance analysis under cyclic loading. Chen et al. [14-16] presented a strengthening scheme for a portal-frame plant structure and established a finite element model for the cross-door frame (in which the spacing between two adjacent beam-column structures is 24 meters) with ANSYS software based on a cable-support system and prestressed reinforcement. Afterwards, cablesupport simulation analysis was conducted to study the changes in the characteristic after the cable-support reinforcement. The reinforcement effects of cable support on portal frames in different prestress conditions were obtained. However, the seismic performance under cyclic loading was not analyzed. Cai [17] took the honeycomb beam column portal frame structure with circular hole and variable section as the research object, carried out quasi-static test on the scale rigid frame model, and obtained the restoring force model of the structure, He also explored the effects of the height of column webs, as well as the spans of rigid frames on this type of rigid frame while no in-depth study on beamcolumn nodes was conducted. Li et al. [18] carried out force analysis on the wind-resisting columns of portal frames and connection of lower flanges of gable beams by vertical slotted-hole bolts and compared wind load coefficients in different conditions that concerned open purlins. However, the seismic performance under cyclic loading was not analyzed. Zhao et al. [19-20] proposed and verified two bolting approaches to current $\Gamma$-shaped beam-column nodes of portal frames with bonded steel reinforcement without exploring other parameters, such as webs and flanges.

The aforementioned studies concentrate on the section shape, spans, column distance, and bolts of portal frames, as well as theoretical calculation, yet pay little attention to the multi-factor analysis of beam-column nodes, especially studies that are associated with stress performance of node domains. In this work, a beam-column connection node model for portal frames was set up with finite element software ANSYS. Its stress performance was studied systematically to analyze the effects of end plate thickness, bolt diameters, friction coefficients, and the ways of endplate placement on bearing capacity and hysteretic performance of specimens. On this basis, new beam-column nodes of portal frames were established. Moreover, these results provide reference for the design and application of portal frames.

The remainder of this study is organized as follows. Section 3 sets up a basic model for portal frames in accordance with a single-floor-and-span plant design. Section 4 analyzes the force performance of monotonic load, cyclic load, rigidity degeneration, node domains, and bolts and determines the characteristics of new beam-column nodes of portal frames. Section 5 summarizes and draws the conclusions. 


\section{Methodology}

\subsection{Design of finite element specimens}

(1) The BASE specimen

The BASE specimen was determined in accordance with a single-floor-and-span plant design. The plant has no crane beam with a span of 21 meters, a column distance of 6 meters, eaves height of 7.5 meters, and a gradient of $1 / 10$. The rigid frame consists of equal-section beams and columns under seismic precautionary intensity of 8 on a second-class site. Other load values are illustrated as follows:

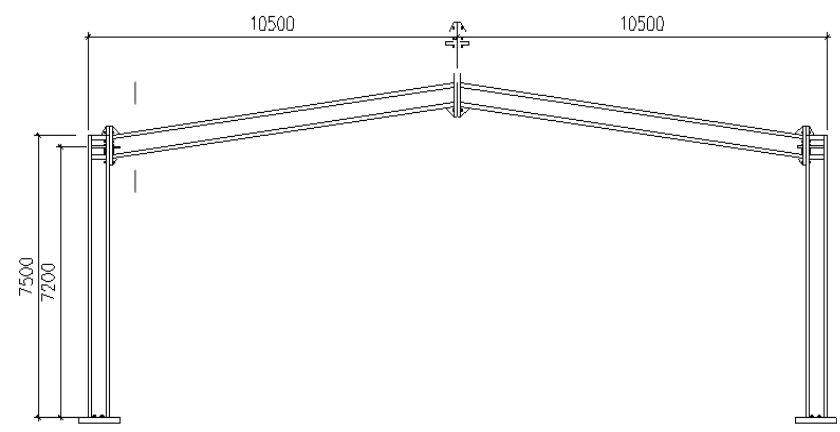

Fig. 1. Portal frame 1:100

a. Standard values of permanent load

Plate and insulation layer $\quad 0.25 \mathrm{KN} / \mathrm{m}^{2}$

Purlin $\quad 0.05 \mathrm{KN} / \mathrm{m}^{2}$

Suspension equipment $\quad 0.20 \mathrm{KN} / \mathrm{m}^{2}$

b. Standard values of variable load

$$
0.5 \mathrm{KN} / \mathrm{m}^{2}
$$

Larger value of live load on floor and snow load 0.3 $K N / m^{2}$

c. Standard values of wind load

Basic wind load: $0.4 \mathrm{KN} / \mathrm{m}^{2}$; ground roughness coefficients belong to Type B: variation coefficients of wind load height are applied in accordance with the regulations of the Load Code for the Design of Building Structures. With a structural mechanics solver, the following combined internal force graphs are obtained:

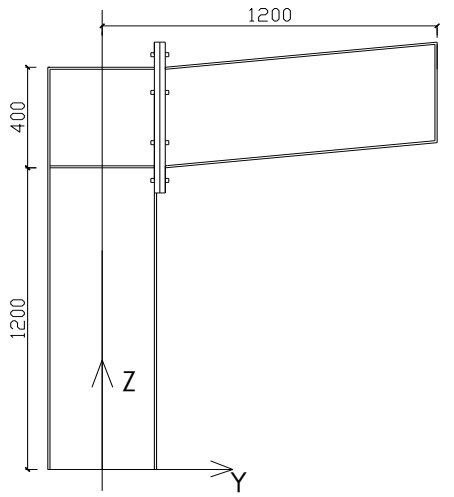

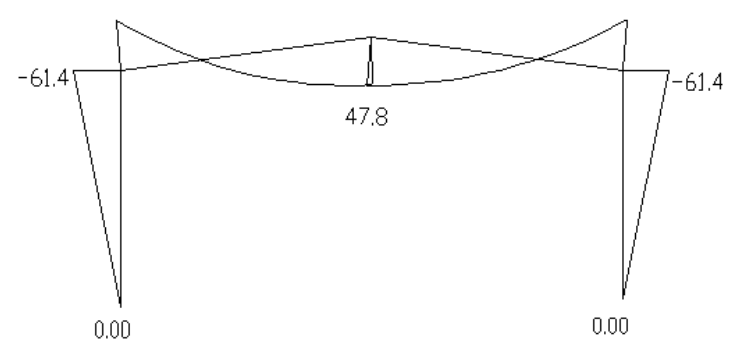

(a) Combined bending moment $\mathrm{M}(\mathrm{KN} / \mathrm{m} 2)$

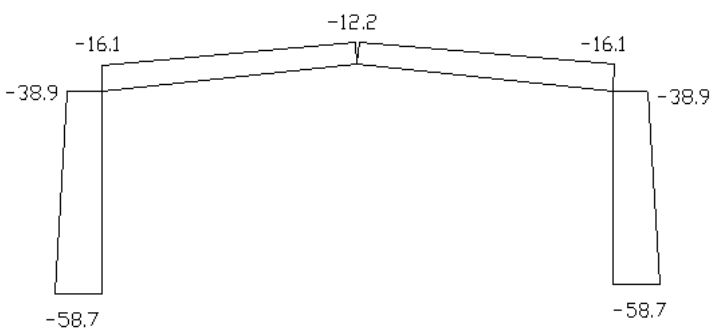

(b) Combined axial force $\mathrm{N}(\mathrm{KN})$

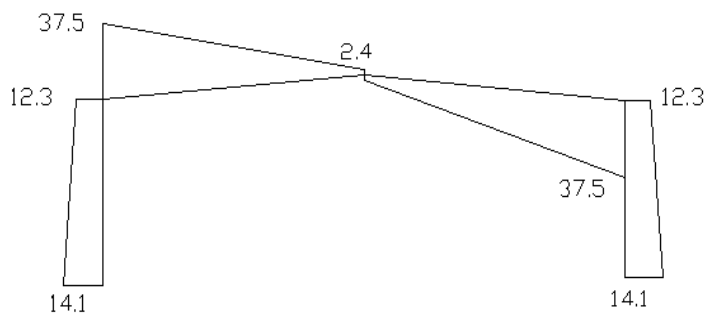

(c) Combined shear $\mathrm{V}(\mathrm{KN})$

Fig.2. Internal force of the BASE specimen

According to the calculation, Figure 3 and Table 1 show the section dimensions of the BASE specimen. As the range of nodes that influences the columns mainly covers double end-plate height, the column height, beam length, and endplate thickness are set as $1.6 \mathrm{~m}, 1.2 \mathrm{~m}$, and $20 \mathrm{~mm}$, respectively. A total of 8 high-strength bolts of 10.9 and M20 with a friction coefficient of 0.4 are also available. Figure 4.3 shows the plane dimensions of end plates and bolt arrangement. Nearly all materials are of Q235, except highstrength bolts. The preload is $155 \mathrm{KN}$.

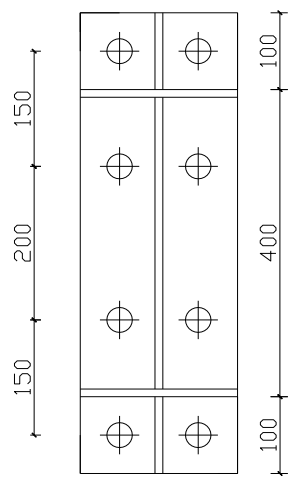

Fig.3. Dimensions of the BASE specim

Table. 1. Details of beams and columns of the basic specimen

\begin{tabular}{lcccc}
\hline Term & Section height & Section width & Thickness of web & Thickness of flange \\
\hline Beam & 400 & 200 & 6 & 8 \\
Column & 400 & 200 & 8 & 10 \\
\hline
\end{tabular}


(2) Checking the calculation of nodes

1). Checking the calculation of node bolt strength

Beam-column nodes are connected by high-strength bolts of 10.9 and M20, where the components are of sand blasting, and the anti-slip coefficient of friction surface $\mu=0.4$. The preload of each bolt is $155 \mathrm{KN}$. As shown in Figure 1, the internal-force design values of the sections are: $\mathrm{N}=-16.09 \mathrm{KN}, \mathrm{V}=37.46 \mathrm{KN}$, and $\mathrm{M}=61.41 \mathrm{KN} \cdot \mathrm{m}$. The tensile force of each bolt is:

$$
\begin{aligned}
& N_{t 1}=\frac{M_{y 1}}{\sum y_{i}^{2}}-\frac{N}{n}= \\
& \frac{61.41 \times 0.25}{4 \times\left(0.25^{2}+0.1^{2}\right)}-\frac{16.09}{8}=
\end{aligned}
$$

$50.93<0.8 \times 155=124$

$N_{t 2}=\frac{M_{y 2}}{\sum y_{i}^{2}}-\frac{N}{n}=$

$\frac{61.41 \times 0.1}{4 \times\left(0.25^{2}+0.1^{2}\right)}-\frac{16.09}{8}=19.17$

According to $\frac{N_{v}}{N_{v}^{b}}+\frac{N_{t}}{N p} \leq 1$

$N_{t}=50.93 \mathrm{KN}, N_{v}=4.68 \mathrm{KN}$

$N_{v}^{b}=0.9 \times 0.35 \times 155=55.82 \mathrm{KN}$

$N_{t}^{b}=0.8 \times 155=124 K N$

$\frac{4.68}{55.82}+\frac{50.93}{124}=0.4945<1.0$

Hence, these bolts satisfy the standard.

2). Checking calculation of end-plate thickness

End-plate thickness $\mathrm{t}=20 \mathrm{~mm}$

Bolt thickness of the first row:

$t \geq \sqrt{\frac{6 e_{f} N_{t}}{b f}}=\sqrt{\frac{6 \times 50 \times 50.9 \times 10^{3}}{200 \times 205}}=19.2 \mathrm{~mm}$

Bolt thickness of the second row:

$$
\begin{aligned}
& t \geq \sqrt{\frac{6 e_{f} e_{w} N_{t}}{\left[e_{w} b+2 e_{f}\left(e_{f}+e_{t}\right)\right] f}} \\
& =\sqrt{\frac{6 \times 50 \times 50 \times 19.7 \times 10^{3}}{[50 \times 200+2 \times 50 \times(50+50)] \times 250}}=8.49 \mathrm{~mm}
\end{aligned}
$$

Obviously, $\mathrm{t}=20 \mathrm{~mm}$ meets the requirements

3). Checking the calculation of shear-resisting node domains

$$
\begin{aligned}
& \tau=\frac{3}{4} \times \frac{M_{1}+M_{2}}{a b t} \leq f_{v} \\
& =\frac{3}{4} \times \frac{2 \times 61.4 \times 10^{6}}{8 \times(400-200) \times(400-20)} \\
& =79.725 \mathrm{~N} / \mathrm{mm}^{2} \leq f_{v}=125 \mathrm{~N} / \mathrm{mm}^{2}
\end{aligned}
$$

These node domains meet the specification of the shear-resisting structure.

\subsection{Selection of constitutive models for material}

Based on the material characteristics obtained by a few scholars through tests, ANSYS adopts a MKIN model. In accordance with tensile tests, the material is isotropic with an elastic modulus of $2.06 \times 10^{5} \mathrm{MPa}$ and a Poisson ratio of 0.3 .

According to the material characteristics in the experiments, when equivalent stress exceeds the yield stress of the material, the directions of impending plastic deformation and strain are determined in the light of Von Mises yield criteria and the plastic flow law. In ANSYS, the material models of Q235 structure steel are defined, where welding rods are of E43 and bolts of M20 and 10.9 highstrength bolts. Besides, its tress strain is simplified as an approximate threefold line (Figure 4).

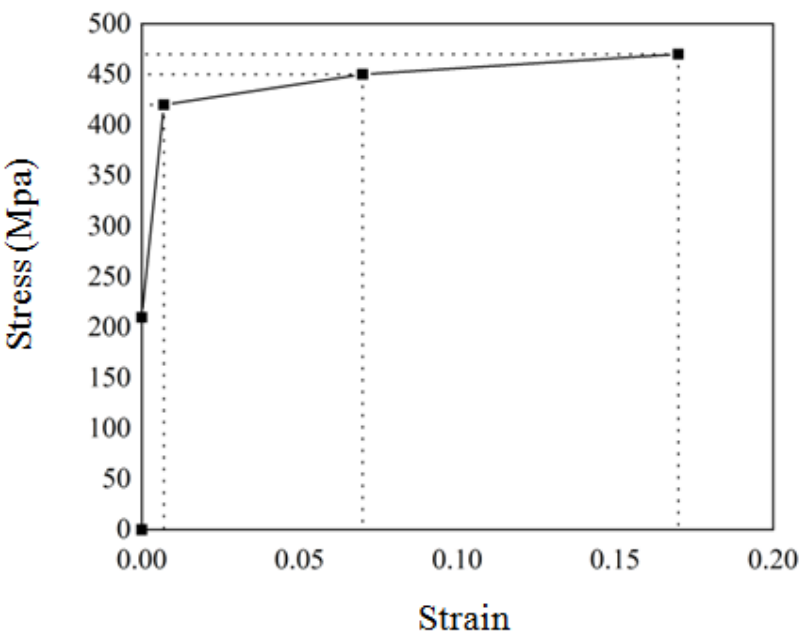

(a) Stress strain of steel plates

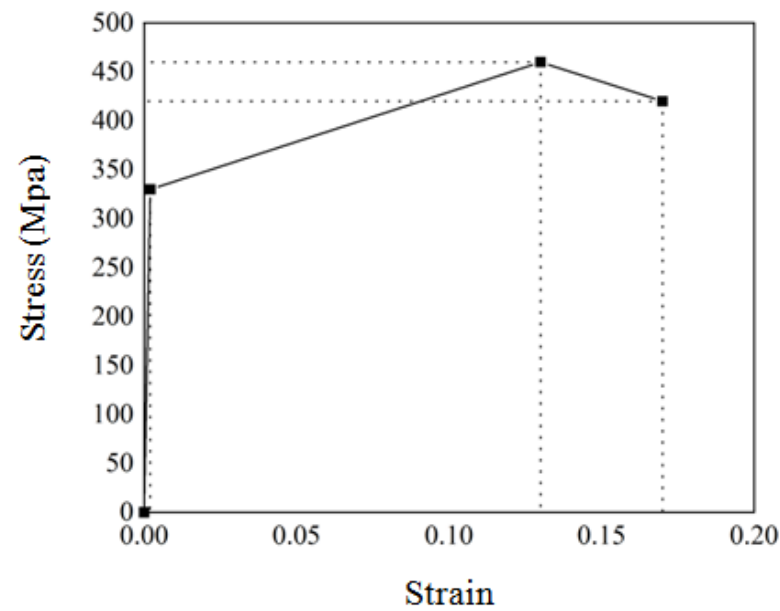

(b) Stress strain of welds 


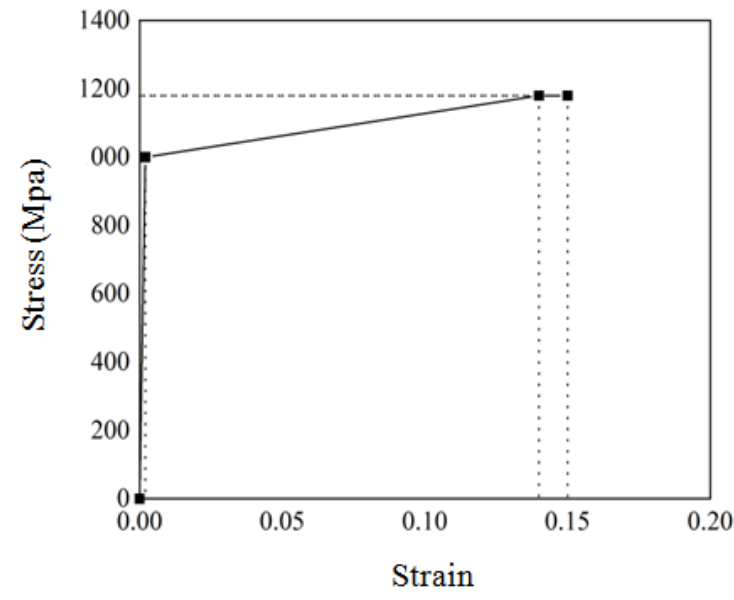

(c) Stress strain of bolts

Fig. 4. Stress strain of material

\subsection{Constraint conditions, interface, and grid division}

Boundary constraint conditions of the model: To avoid the lateral buckling of the model, a constraint along the Zdirection is added on the column top. To simulate the stress performance of the portal frame, constraints along X-, Y-, and Z-directions are added on the column bottom. In addition, a displacement-coupling constraint is added on the free end of the beam. The displacement vertical to coupling can be found in Figure 5.

To satisfy the actual stress conditions, the friction between bolt holes and shanks, column flange plates and end plates, as well as end plates and nuts, is considered. Therefore, units TARGE170 and CONTA174 are used to simulate the surface friction, in which the initial intrusion between hole walls is not considered, and the actual friction coefficients between plates are adopted (Figure 6).

This study used the division of finite element specimen of beam-column end-plate connection by the unit form provided by ANSYS. Overall grid division of the 3D finite element model of the BASE specimen can be found in Fig. 7(a). Unit Solid92 is applied to the free division of end plates and bolts, while unit Solid45 is adopted in the other parts, as shown in Fig. 7(b), (c) and (d).

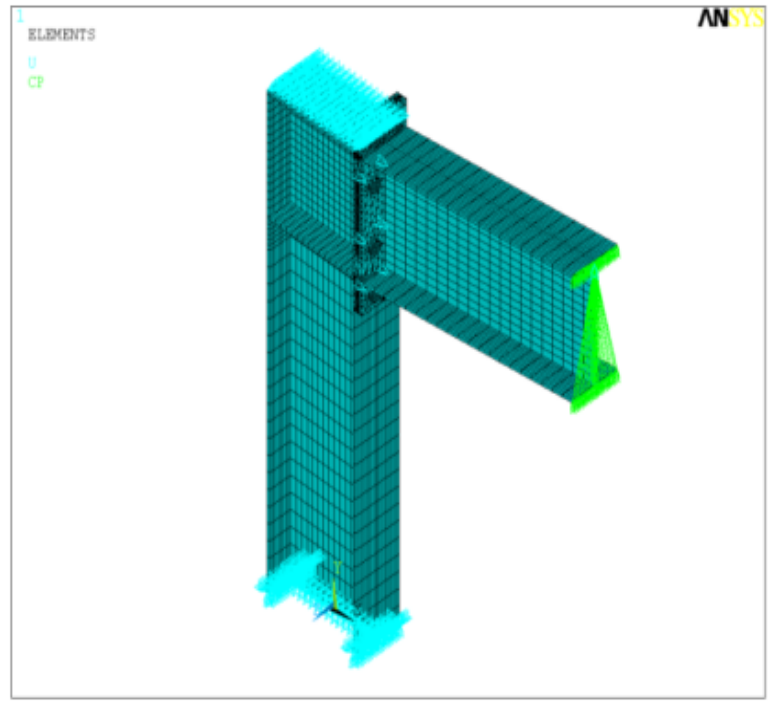

Fig.5. Specimen constraint

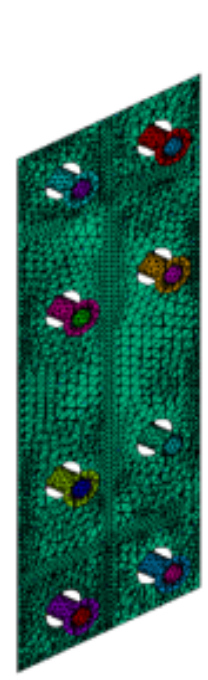

Fig.6. Interface

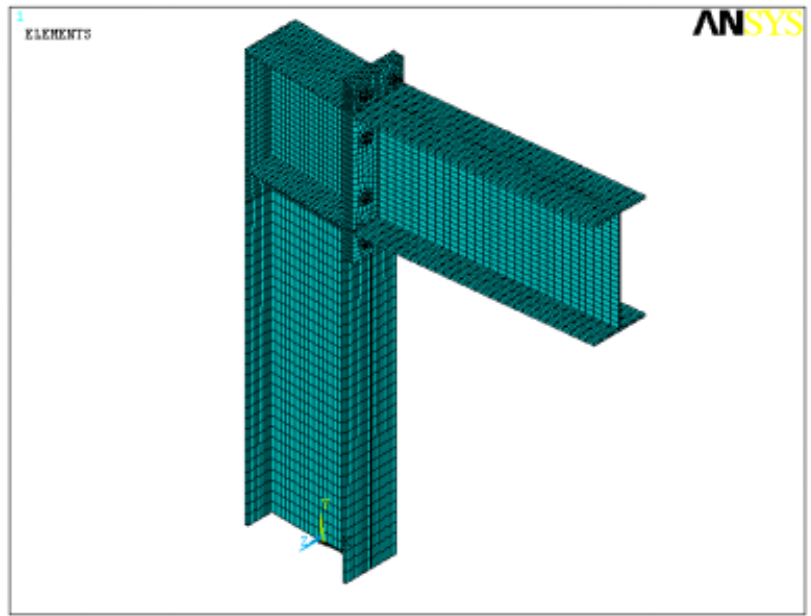

(a) Grid division of the BASE specimen

\section{NN}

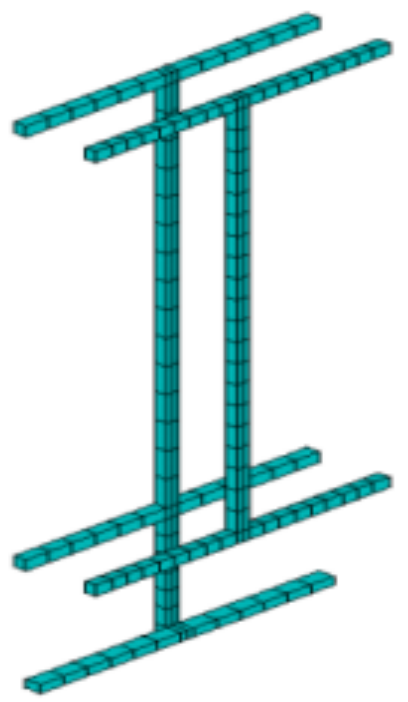

(b) Grid division of wields 


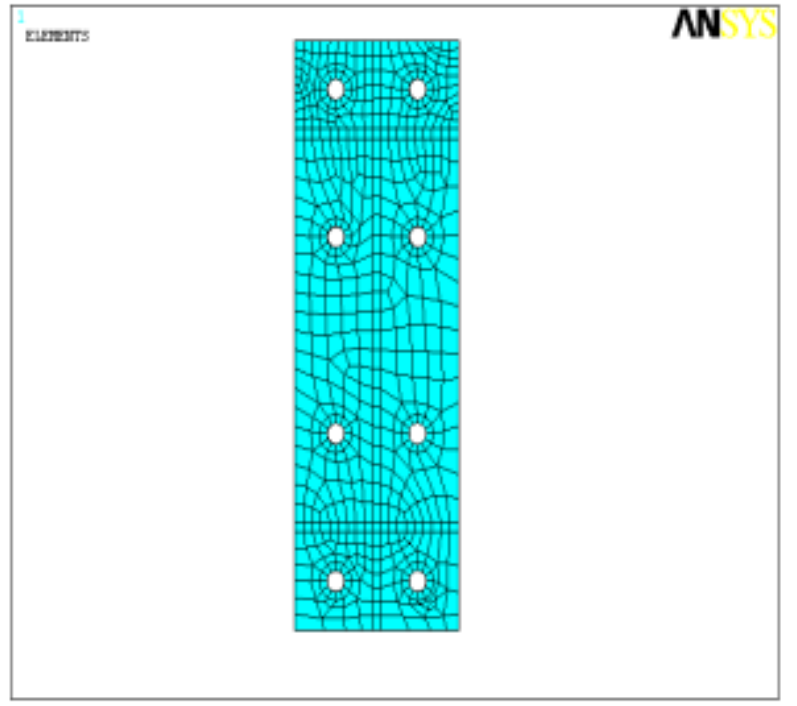

(c) Grid division of end plates

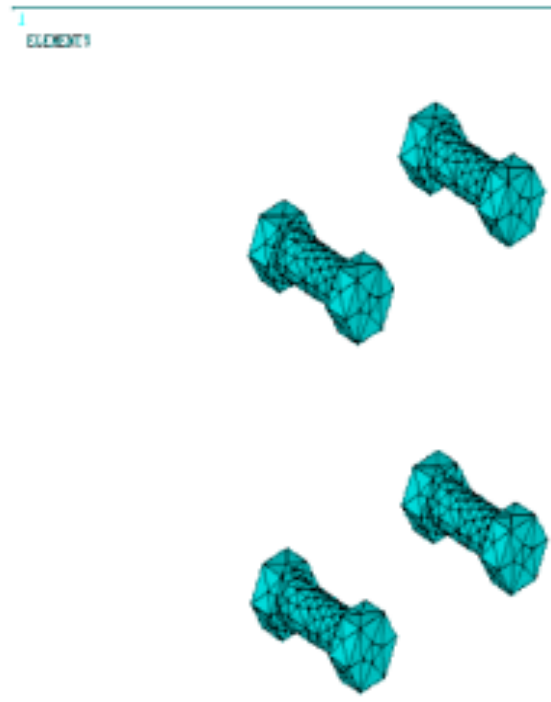

(d) Grid division of bolts

Fig.7. Grid division of the model

\subsection{Loading system}

A full loading system of ECCS is adopted to reflect the behavior of portal-frame nodes during positive-andnegative-direction monotonic loading. Based on the loaddisplacement curve of monotonic loading, $\Delta_{y}^{+}, \Delta_{y}^{-}, F_{y}^{+}$and $F_{y}^{-}$are determined through calculation. "G. Y. M. M" is adopted to determine the yield point of the specimen (Figure 8). A tangent line is set from the origin, that is, Line OB of theoretical elasticity value, crossing the horizontal line of Point D of ultimate load and intersecting in Point B. A vertical line of the horizontal axis is set via Point $\mathrm{B}$, thereby intersecting Point $\mathrm{A}$ with Curve P- $\Delta$. Points $\mathrm{O}$ and $\mathrm{A}$ are connected and extended to Line BD, thereby crossing Point C. Then, a vertical line of horizontal axis is set via Point $C$, thereby intersecting in Point $\mathrm{E}$ with Curve P- $\Delta$. As a result, Point $\mathrm{E}$ is the yield point, namely, $\mathrm{E}\left(p_{y}, \Delta_{y}\right)$ refers to yield load and displacement. According to the row of $\Delta_{y} / 4, \Delta_{y} / 2, \Delta_{y}, \Delta_{y} 3 / 2,2 \Delta_{y}, \Delta_{y} 5 / 2$, and $3 \Delta_{y} \ldots$, the cyclic loading of all specimens is conducted to cycle once per level of displacement until they are broken.

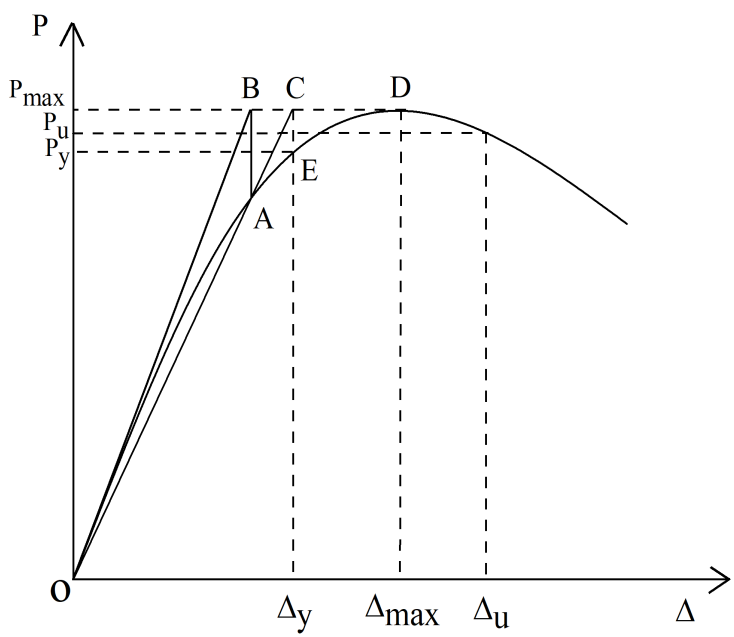

Fig.8. Determination of yield points

\subsection{Design of new nodes}

(1) According to the BASE specimen, the node domain stress concentrates obviously. To ensure the design principle of "strong node and weak rod," stiffening ribs are added in the node domains to strengthen node rigidity and enhance the bearing capacity of specimens. Modified Model IN1 can be found in Fig.9(b).

(2) According to the current speculations in China, end-plate connected is regarded as a rigid connection in calculation. Suppose that an end plate rotates around the central axis on a plane, where the tensile force of the outset-row bolts in the stretching area is maximum. However, ANSYS results indicate that the maximum tensile force is from the first-row bolts of the stretched flanges, and the rotation center of the end plate is on the center line of the flanges. Stiffening ribs can be added on the external stretching area to increase the tensile force of bolts on the end-plate stretching area and enhance the anti-bending performance of nodes and seismic performance of end-plate connection. Thus, Modified Model IN2 is proposed Fig.9(c).

(3) Fig.9(d) presents Modified Model IN3, in which an axillary arc plate is placed to enhance the interface with beam-column connection, thereby reducing the flange yield failure caused by stress concentration. At the same time, the axillary arc plate is a strong supplement for the end-plate connection, thus enhancing the shear-bearing capacity of node domains, harmonizing beams and columns, and delivering external load to the lower structure.

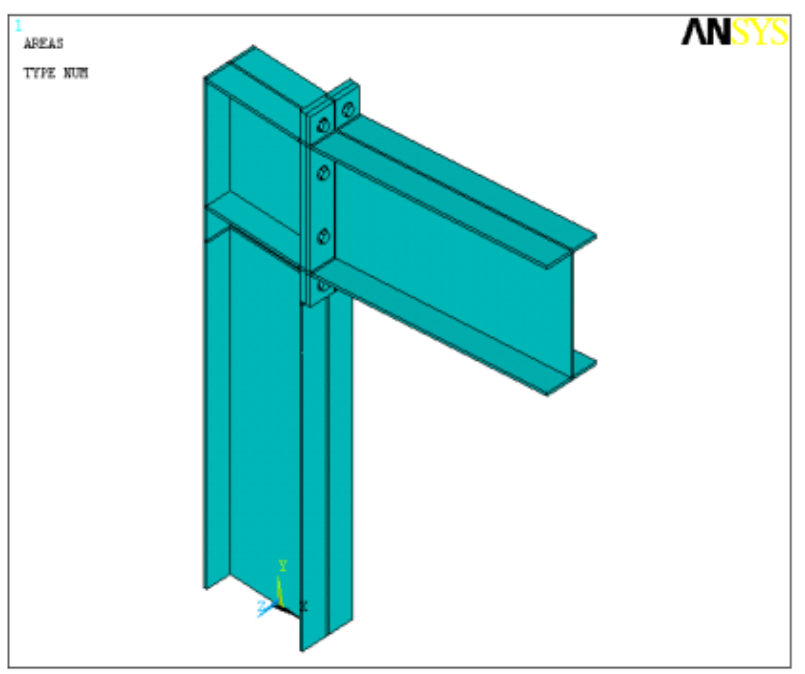

(a) BACE 


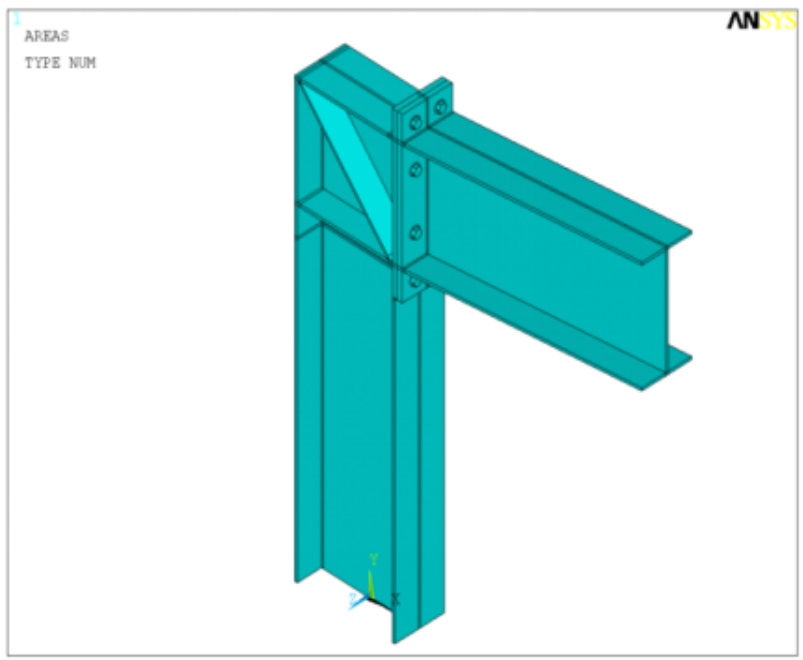

(b) IN1

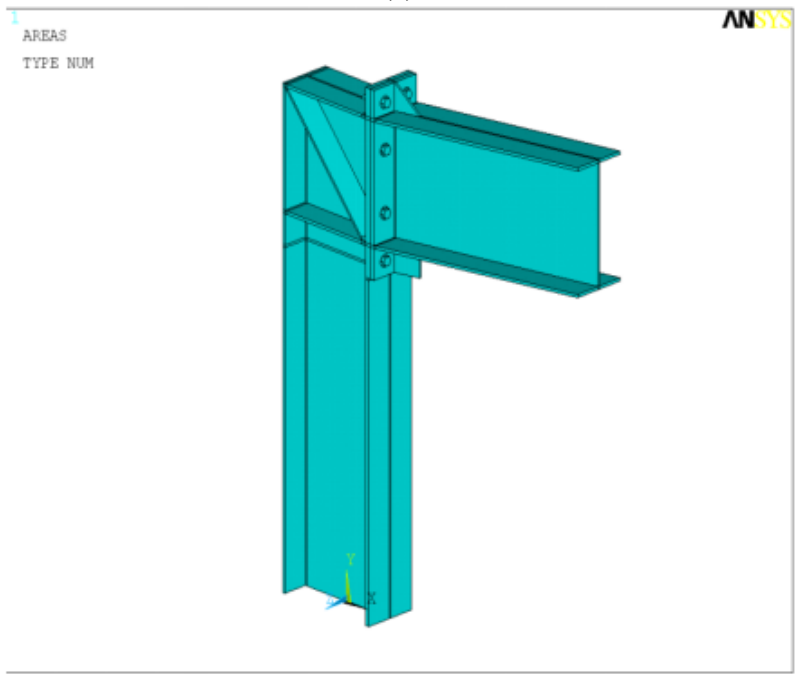

(c) IN2

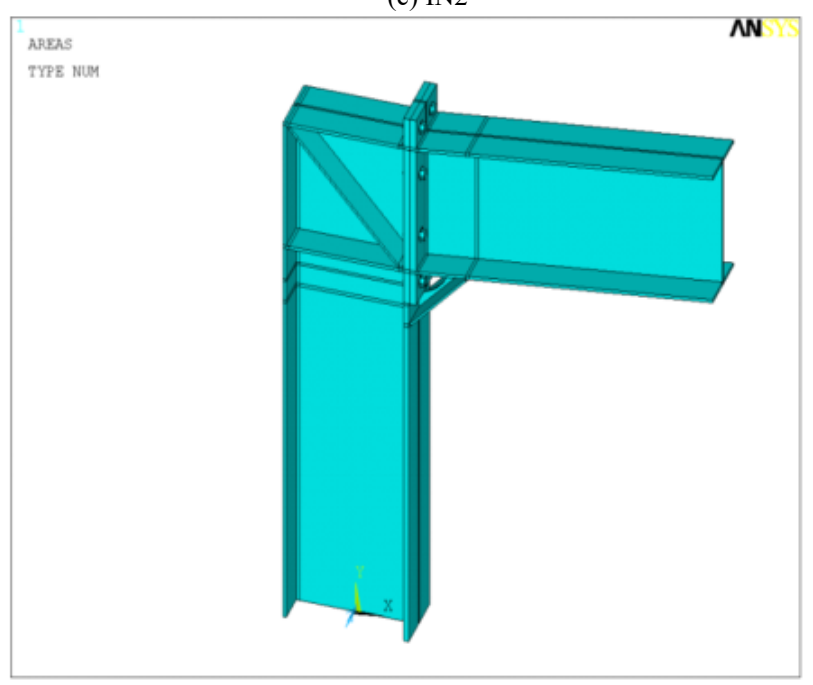

(d) IN3

Fig. 9. Modified specimen models

\section{Result Analysis and Discussion}

4.1. Load-displacement curve during monotonic loading Figure 10 shows the load-displacement curve during the monotonic loading of modified nodes. When the beam displacement during monotonic loading is less than $10 \mathrm{~mm}$, the model is in an elastic state. When it exceeds $10 \mathrm{~mm}$, it is in a plastic state. In the elastic state, displacements are obviously different under the same load (i.e., BASE, IN1, IN2, and IN3) in a descending order, indicating that the rigidities of modified models, IN2, and IN3 are obviously enhanced. When the beam-end displacement reaches 120 $\mathrm{mm}$, no obvious decline is observed on the loaddisplacement curve, thereby exhibiting good plastic deformation. Thus, it improves the stress performance of nodes and protect node domains and balance force of end plates and node domains. The original rigidity of the IN1 specimen is lower than that of the BASE one. However, when the beam displacement reaches $60 \mathrm{~mm}$, the IN1 curve declines obviously because of the yield failure of column flanges caused by node domain reinforcement. IN2 and IN3 improved after strengthening the flanges inside the columns. In addition to node domain reinforcement, the overall stress performance of specimens also requires coordination.

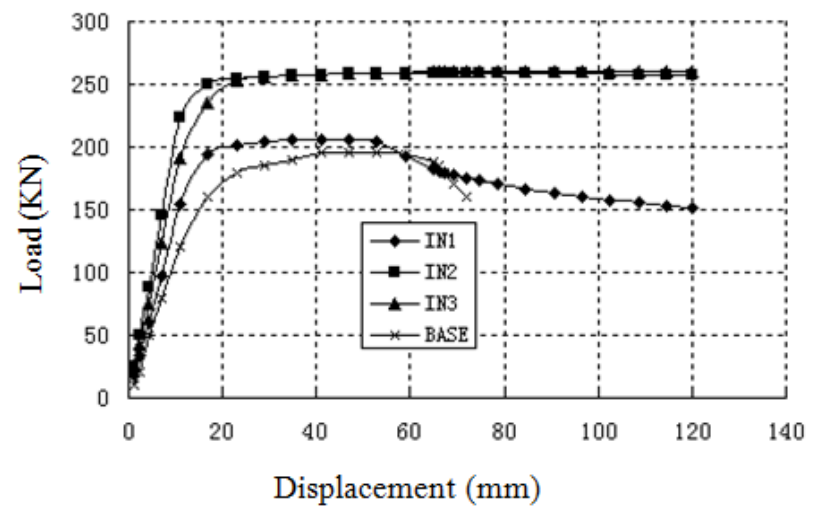

Fig.10. Load-displacement curve during the monotonic loading of modified node

\subsection{Load-displacement hysteretic curve during cyclic loading}

As shown in Figure 11, when the free-end displacement of beams is short, all the four models present good elastic properties, where they are in an elastic state with an extremely small hysteretic area. Their plastic deformations and bearing capacity increase with the displacement. With further increase in load, the area inside each hysteretic curve expands, where model rigidity begins to degenerate, indicating a nonlinear stage of structure. Next, when the BASE beam displacement reaches $60 \mathrm{~mm}$, yield failure of nodes occurs, For this network, PSO-net obtains five clusters, as shown in Fig. 11(a).The addition of stiffening ribs in the node domains strengthens the node rigidity of $\mathrm{IN} 1$, and its tensility drops. As a result, there is an untimely yield failure of stressed flanges during cyclic loading from $3 \Delta_{y}^{+}$to $3 \Delta_{y}^{-}$. Thus, strengthening a local part of a specimen cannot guarantee the enhancement of its overall performance. Besides, harmony of a specimen should be considered, as shown in Fig. 11(b). Specimens IN2 and IN3 indicate the modification that involves the thickness of flanges inside columns above $12 \mathrm{~mm}$, where stiffening ribs and axillary arc plates are installed. The bearing capacity and seismic performance are good, as shown in Fig. 11(c) and (d).

\subsection{Framework curves and rigidity degeneration}

As shown in Figure 12 (a), the framework curves increase obviously after the modification with great enhancement of bearing capacity, especially, the ultimate bearing capacity of IN2 and IN3 reaches $260 \mathrm{KN}$. When the beam displacement of IN3 reaches $90 \mathrm{~mm}$, its curve remains upward, which exhibits a good stress performance. Figure 12 (b) indicates 
that when the beam displacement reaches $40 \mathrm{~mm}$ after modification, the curve slope drops dramatically, indicating slow degeneration and ensuring long-term effective usage of structure.

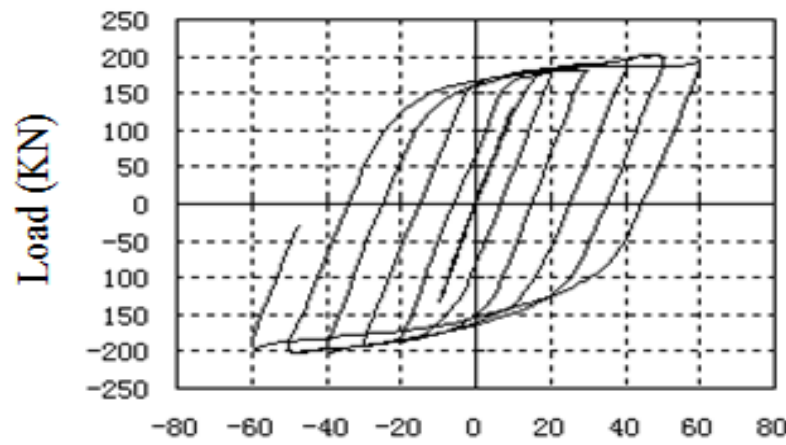

Displacement ( $\mathrm{mm})$

(a) BASE

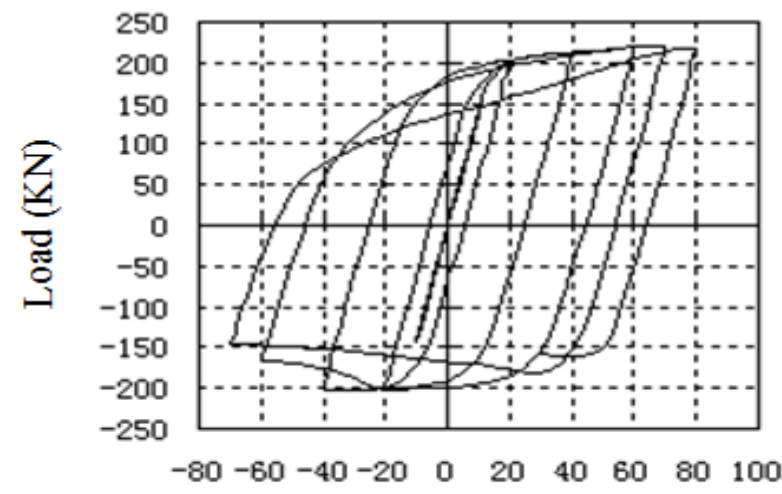

Displacement (mm)

(b) IN1

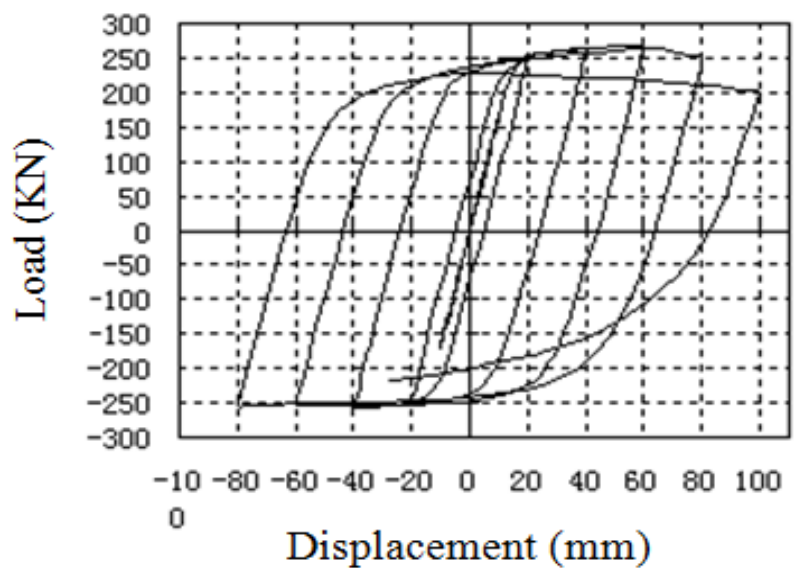

(c) IN2

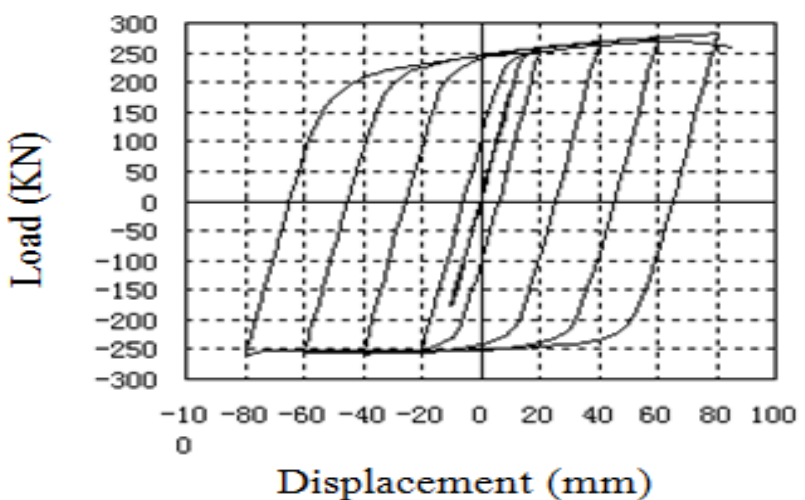

(d) IN3

Fig.11. Hysteretic curves of modified specimens

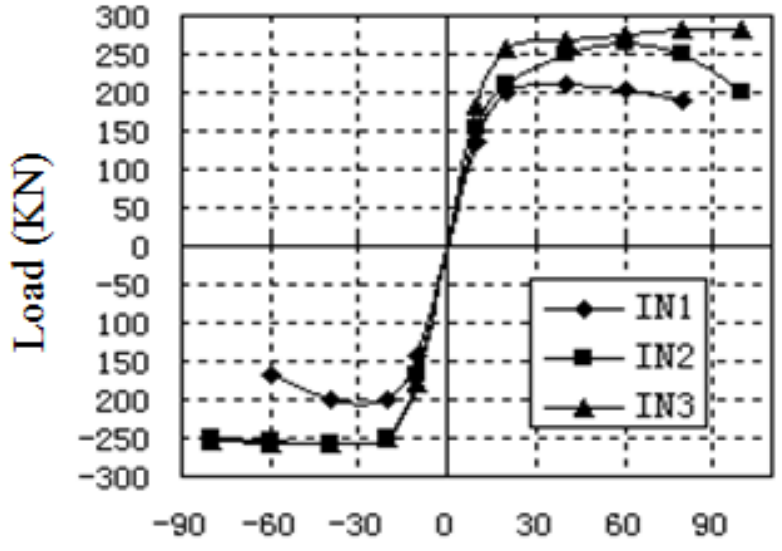

Displacement $(\mathrm{mm})$

(a) Framework curves

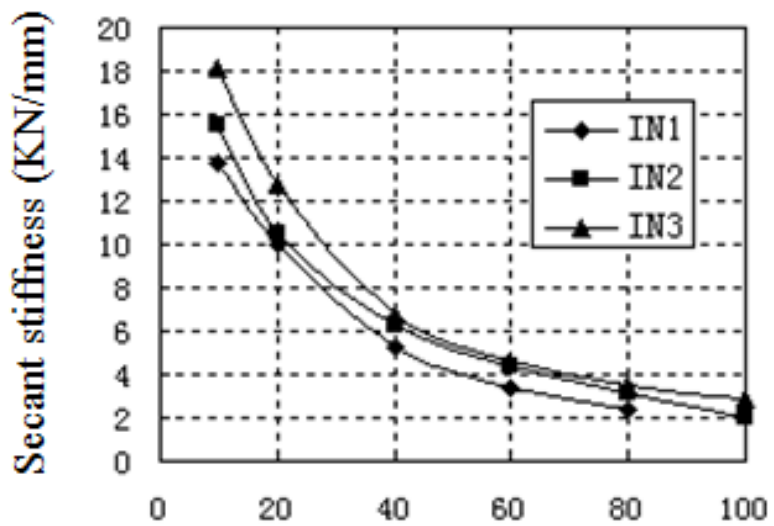

Displacement (mm)

(b) Curves of rigidity degeneration

Fig.12. Curves of modified specimen frameworks and rigidity degeneration

\subsection{Stress analysis of key parts}

(1). Shearing stress of node domains

Figure 13 displays the main shearing stress vector distribution of BASE node domains. The force of the node domains mainly include shearing stress, where the primary shearing stress is found along $45^{\circ}$. The overall model failure is caused by the yield of node-domain column web. To enhance the shear bearing capacity of node domains, stiffening ribs should be added along $45^{\circ}$.

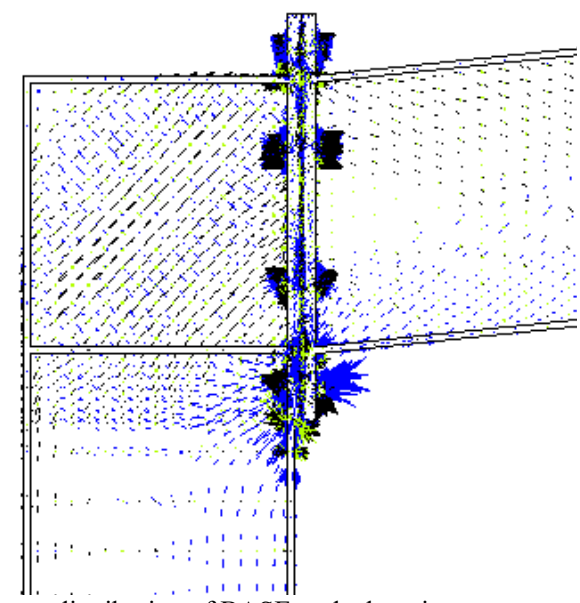

Fig.13. Stress vector distribution of BASE node domains 
Figure 14 shows the node domain deformation when the beam free-end displacement along the Y-axis reaches 60 $\mathrm{mm}$. The mechanical properties of different structured nodes vary greatly. That is, the higher the node integrity is, the higher the rigidity and the smaller the deformation will be. By adding stiffening ribs and axillary arc plates, the node domains of IN1, IN2 and IN3 are well protected to reduce the beam displacements caused by external loading as well as the balance force of end plates and node domains. In addition, their node domain deformations are small during failure with the characteristic of ductile failure, as shown in Fig. 14(b), (c) and (d).

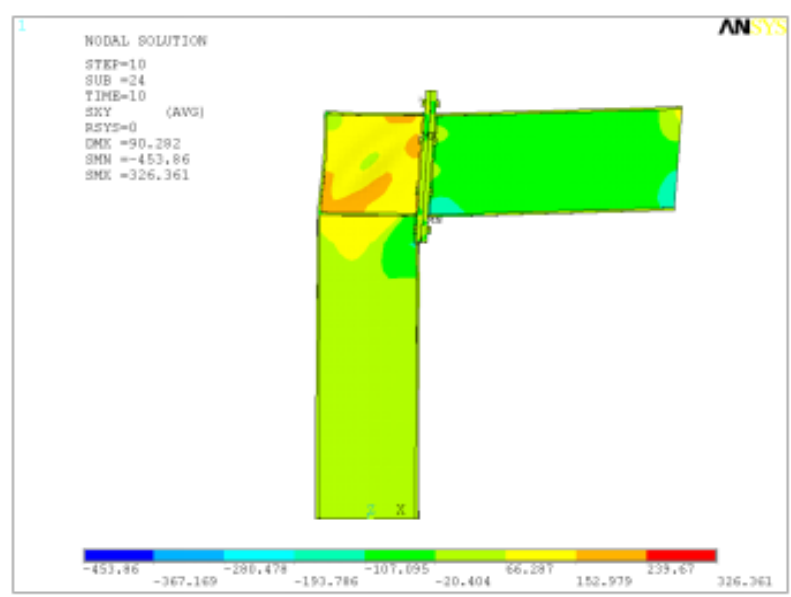

(a) BASE node domain share-xy
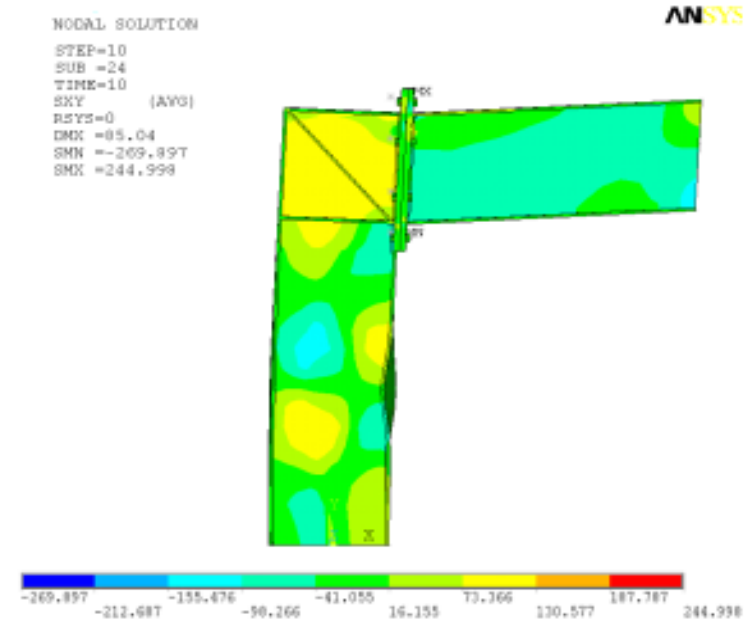

(b) IN1 node domain share-xy
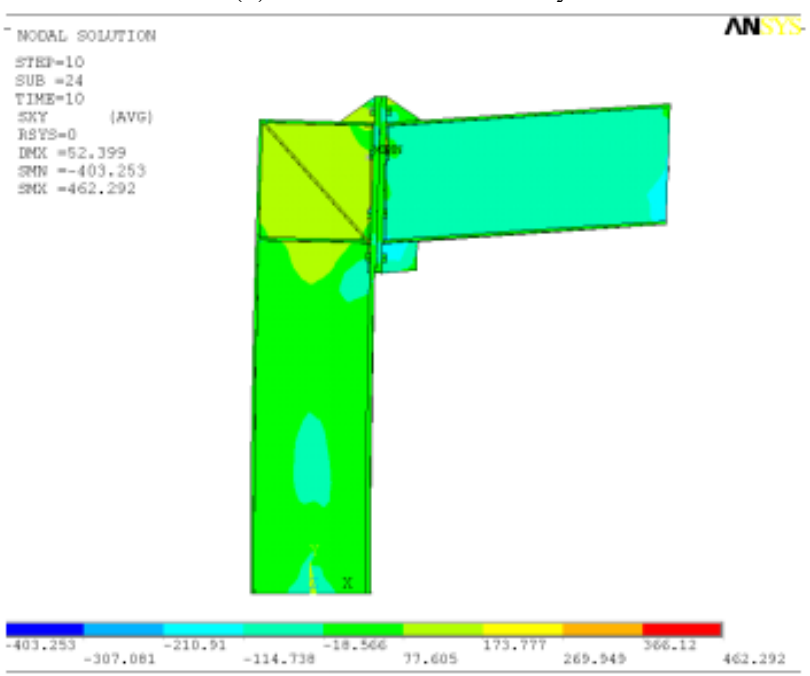

(c) IN2 node domain share-xy

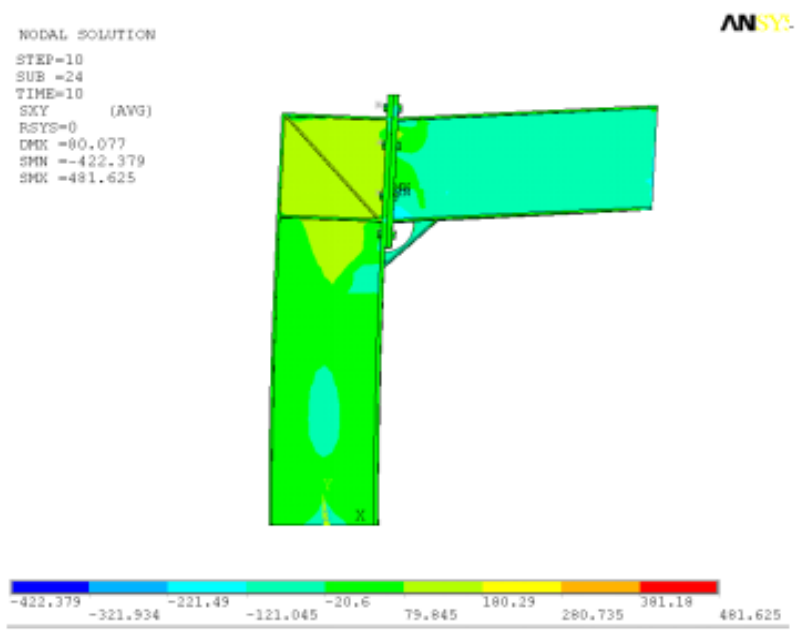

(d) IN3 node domain share-xy

Fig.14.Share graphs of modified specimens

Figure 15 shows the diagonal share of node domains when the beam free-end displacement along the $\mathrm{Y}$-axis reaches $60 \mathrm{~mm}$. The BASE loading is quite uneven because of the buckling deformation of its node domain that led to the failure of the specimen, as shown in Fig. 15(a). Due to enhanced rigidity of IN1 with stiffening ribs, columnstressed flanges are buckled, resulting in inadequate application of the specimen, as shown in Fig.15(b). The node-domain loading of IN2 and IN3 is even and reaches $132 \mathrm{MPa}$, leading to the buckling failure of beam flanges, as shown in Fig. 15(c) and (d).

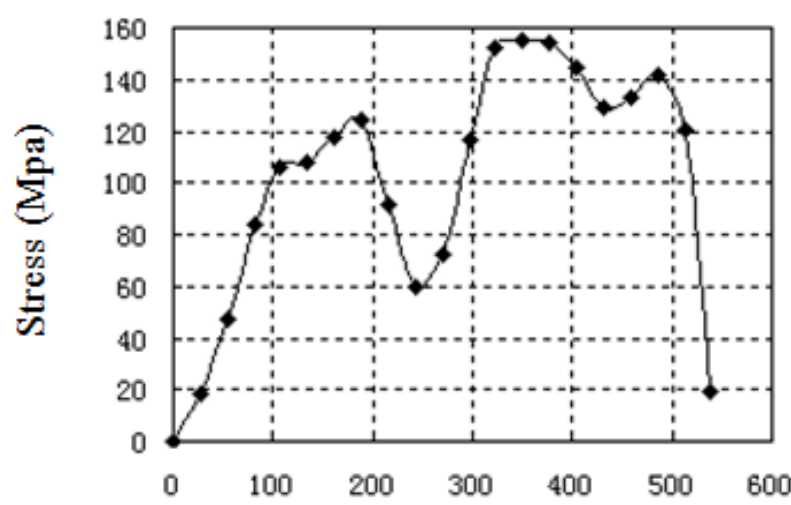

Diagonal length of node field $(\mathrm{mm})$

(a) BASE node domain share-xy

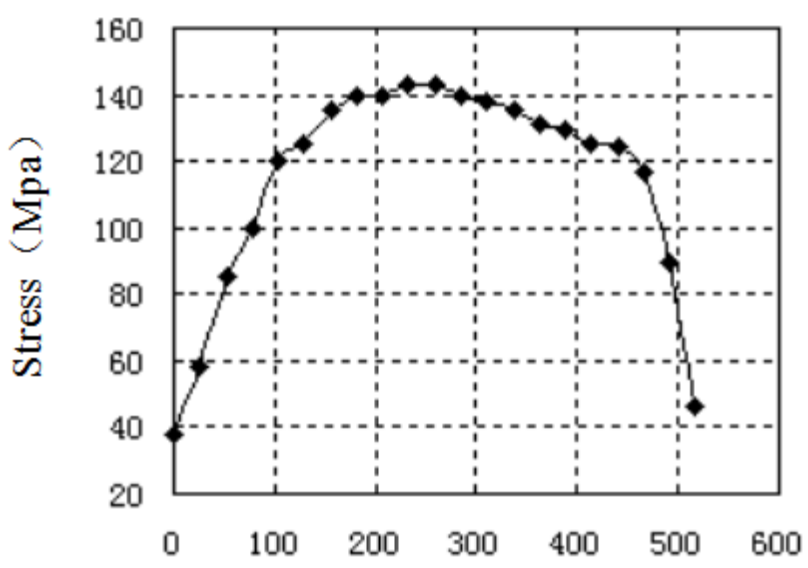

Diagonal length of node field $(\mathrm{mm})$

(b) IN1 node domain share-xy 


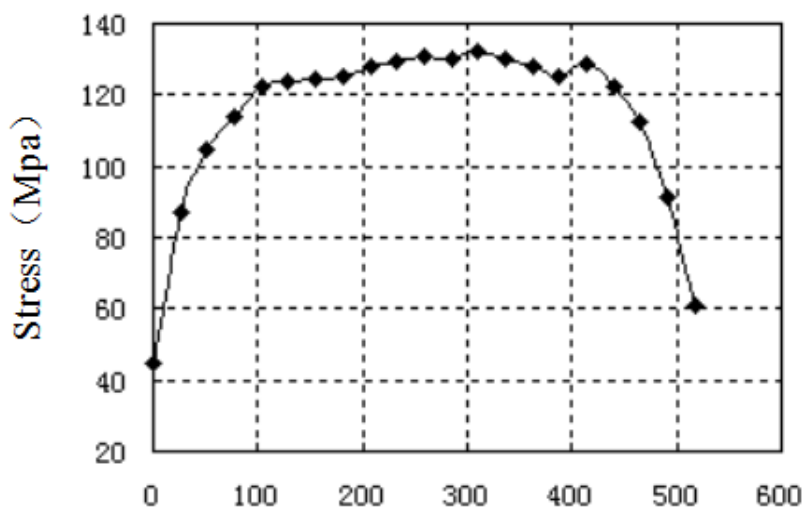

Diagonal length of node field $(\mathrm{mm})$

(c) IN2 node domain share-xy

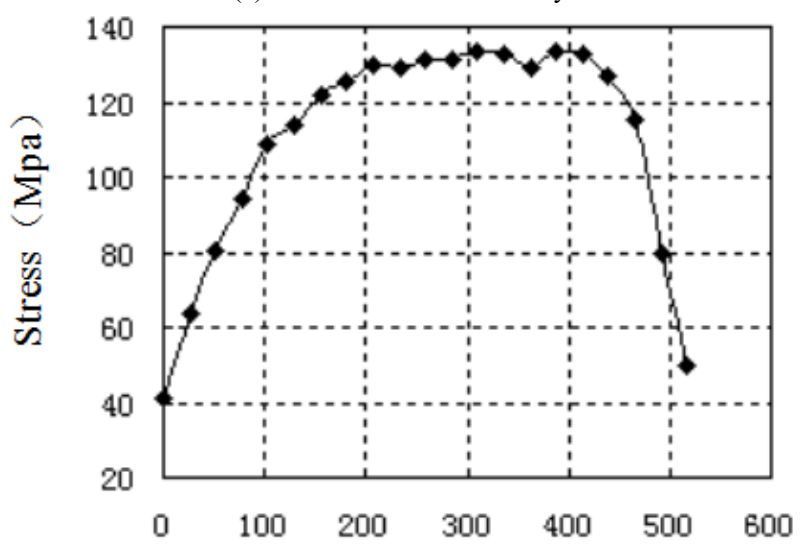

Diagonal length of node field $(\mathrm{mm})$

(d) IN3 node domain share-xy

Fig.15. Diagonal share graphs of modified specimens

(2) Mises stress of column flanges

Figure 16 shows the Mises stress of column flanges when the beam free-end displacement along the Y-axis reaches $60 \mathrm{~mm}$. The Mises stress of flanges inside the columns is greater than those outside, because the flanges inside the columns are near the core of the node domains, which result in concentrated stress. As shown in the figure, the stress distribution of column flanges is quite uneven, and the stress near the node domain is not maximum. The stress grows sharply in the middle and then declines. The reason is that IN1 column-stressed flanges have already been buckled and the stress has exceeded its yield strength, resulting in failure when the beam free-end displacement reaches $60 \mathrm{~mm}$, as shown in Fig.16(a) and (b).

In IN2, the sections of column-stressed flanges increase to $12 \mathrm{~mm}$. The graphs of Mises stress indicate the even loading of stretched and stressed flanges without any apparent fluctuations, contributing to good coordination of the overall stress performance, as shown in Fig.16(c) and (d).

(3) Mises stress of bolts

Figure 17(a) and (b) illustrate the Mises stress along the bolt rods when the beam free-end displacement reaches 60 $\mathrm{mm}$ along the Y-axis. The stress of the second-row bolts is evidently greater than that of the first-row ones, thereby contradicting with the specification that the stress of the stretched first-row bolts is maximum. Besides, IN2 was put forward to improve the coordinating performance of bolts and end plates and avoid the brittle failure caused by the excessive loading of local bolts, which exhibit distinct effects. The stress of the first-row bolts is increased to 504
$\mathrm{MPa}$, whereas that of the second-row ones is enhanced to $545 \mathrm{MPa}$. The bolt stress of both rows tends to be balanced, thereby avoiding the brittle failure caused by bolt rupture and ensuring the combined action of end plates and bolts. As a result, horizontal motion can avoid the buckling failure of end plates, as shown in Fig.17(c) and (d).

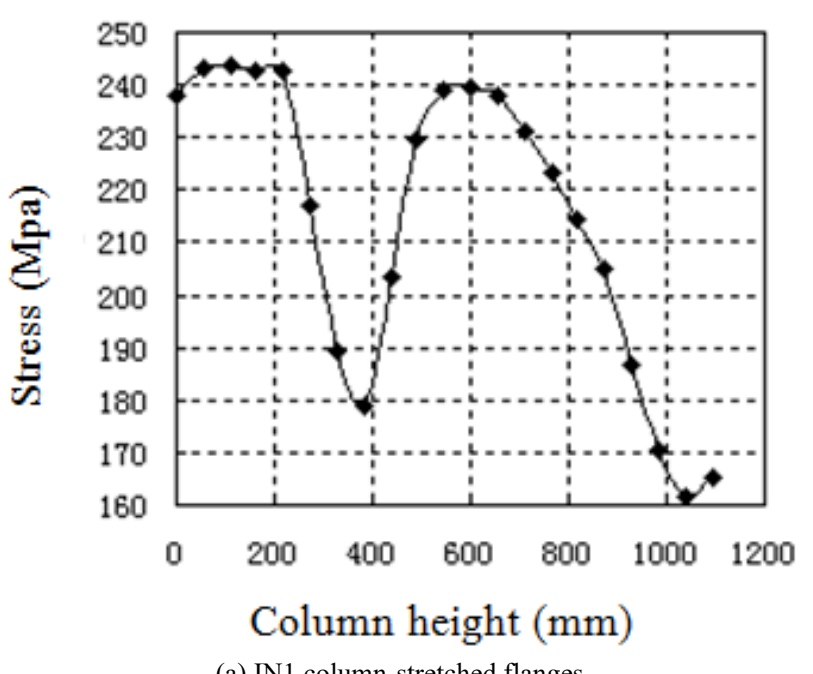

(a) IN1 column-stretched flanges

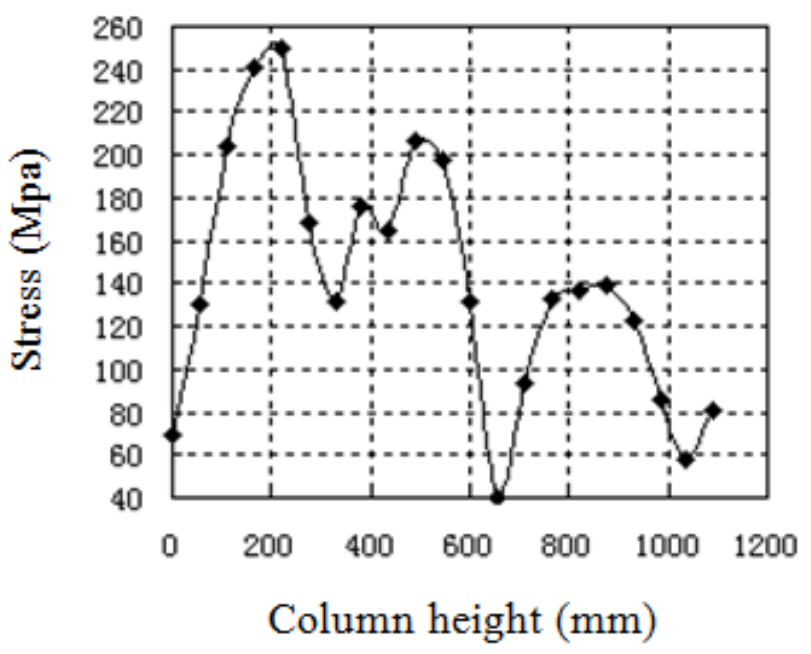

(b) IN1 column-stressed flanges

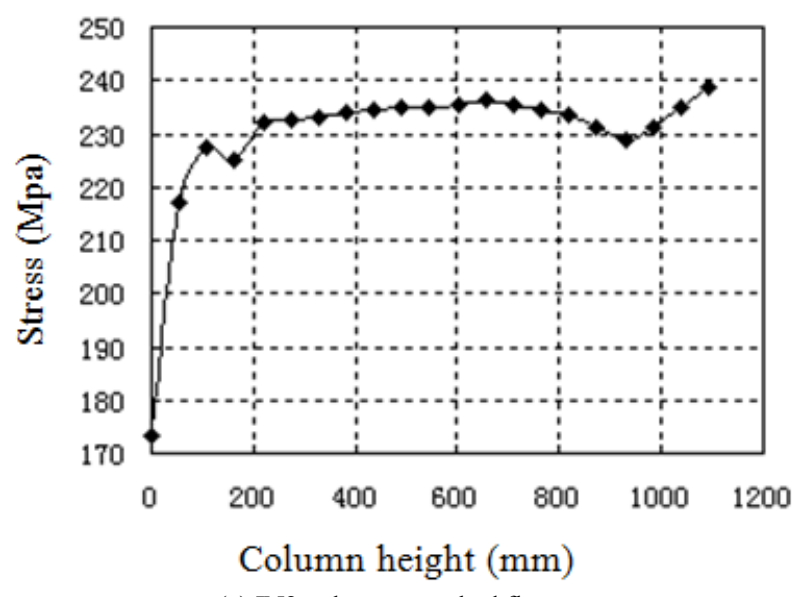

(c) IN2 column-stretched flanges 


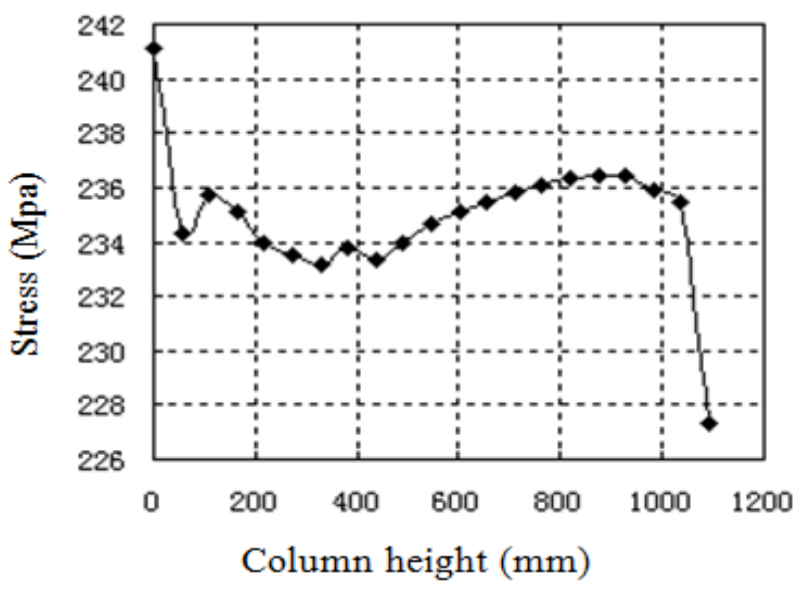

(d) IN2 column-stressed flanges

Fig.16. Stress of column flanges

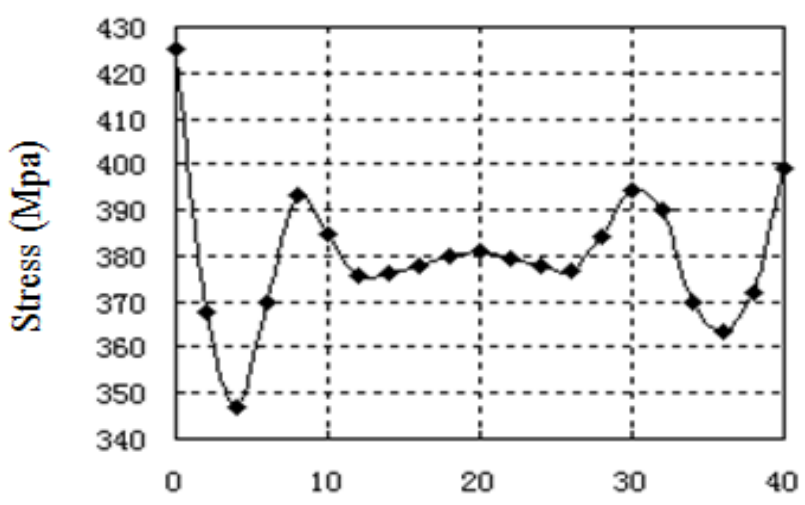

Screw length $(\mathrm{mm})$

(a) First-row bolts of IN1

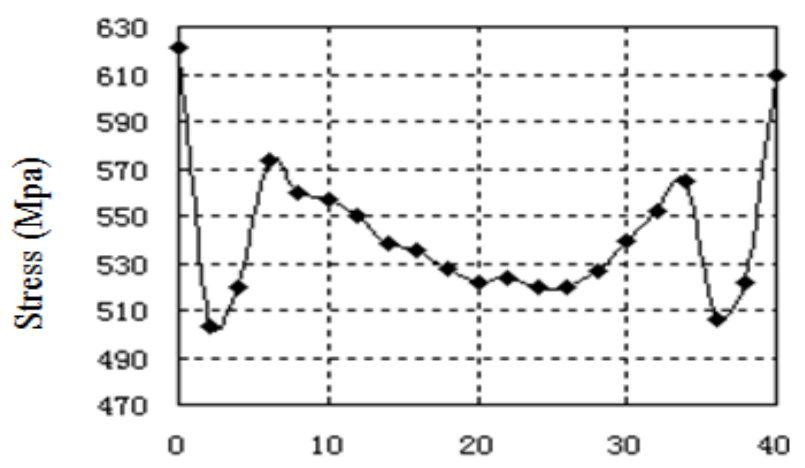

Screw length $(\mathrm{mm})$

(b) Second-row bolts of IN1

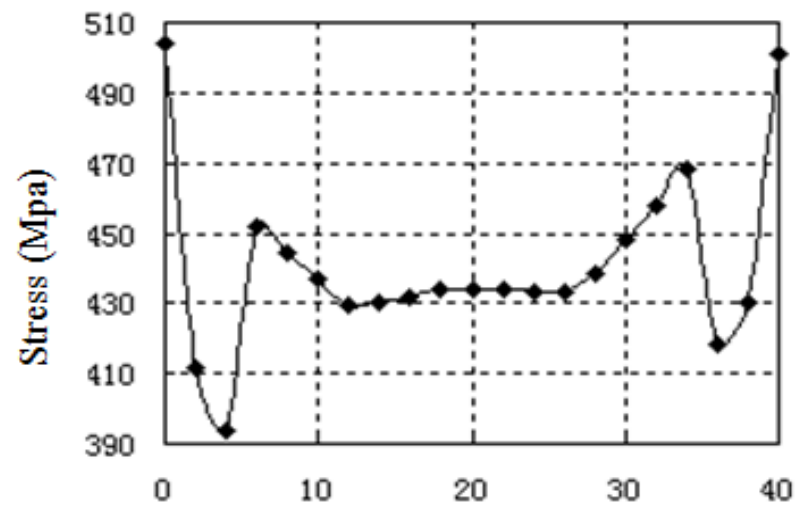

Screw length $(\mathrm{mm})$

(c) First-row bolts of IN2

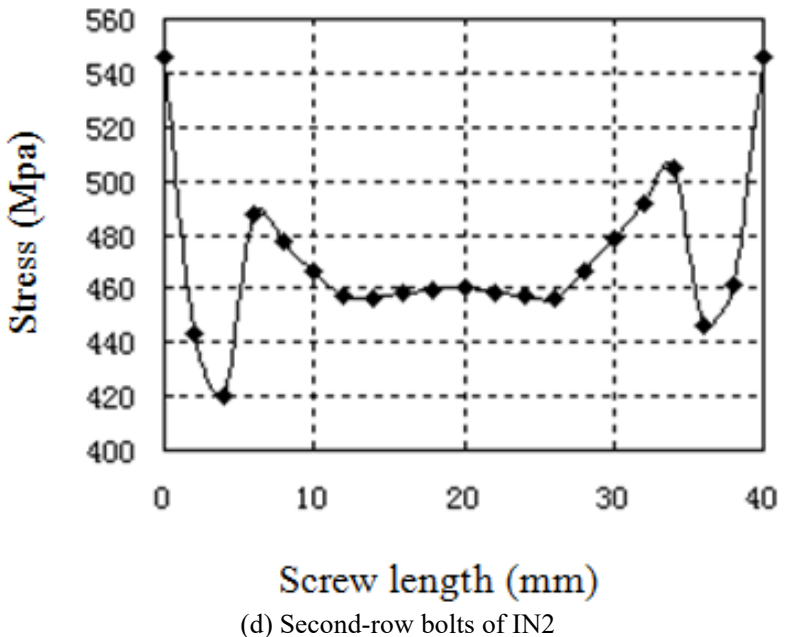

Fig.17. IN2 stress along bolt rods

\section{Conclusions}

To explore the stress characteristics of beam-column nodes of portal frames and reveal the influences of factors, such as end plate thickness, end-plate placement, and bolt diameters, on nodes, this study established basic and modified models based on a single-floor-and-span portal-frame plant through numerical simulation. These models analyzed different parameters, including monotonic loading, cyclic loading, shear of node domains, as well as stress of column flanges and bolt stress. The following conclusions could be drawn:

(1) The eventual failure of the BASE specimen refers to shear buckling of node-domain column webs. Stiffening ribs should be installed $45^{\circ}$ along the node domain. In Modified Model IN1, the stress performance of node domains is enhanced while buckling failure of column flanges caused by strengthened node rigidity exists. Hence, the coordination of various parts of a specimen should be considered in specimen reinforcement.

(2) Modified Model IN2 was proposed on the basis of the increase in the thickness of flanges inside columns. It improves the tensile force of the first-row bolts outside stretched flanges effectively. Besides, the rotation center of its end plates is on the center line of the flanges. It guarantees the rotation of end plates on the same plane and increases the tensile force of bolts outside stretched end plates, thereby contributing to the improvement of the antibending performance of nodes and seismic performance of end plates. Load-displacement and hysteretic curves show a good overall performance of the specimen with ultimate bearing capacity of $256 \mathrm{KN}$. The ductile failure of beambelow flanges occurs when the hysteretic curve is plump and its beam-end displacement reaches $80 \mathrm{~mm}$.

(3) Modified Model IN3 includes axillary arc nodes and is connected by bolts and welding. It is characterized by high welding strength and good connection ductility of bolts and end plates, which avoids the contradiction between high rigidity and poor ductility. As a result, it further improves the bearing capacity of nodes. The large interface between axillary arc plates and beam-column connection reduces the yield failure of beam-column flanges that resulted from stress concentration. At the same time, the axillary arc plate is a strong supplement for the end-plate connection, hence enhancing the shear-bearing capacity of node domains, harmonizing beams and columns, and delivering external load to the lower structure. 


\section{Acknowledgements}

This work was supported by the Science Project Higher Education Institutions of China (ZC2021208).
This is an Open Access article distributed under the terms of the Creative Commons Attribution License.

\section{References}

1. Xue, M. S., "Study on the influence of joint stiffness on the design of light portal frame structure ". Anhui Architecture, 26 (12), 2019,pp.89-90.

2. Zhang, W., "Experimental analysis on mechanical behavior of high strength bolts in beam column semi-rigid joints of portal frame ".Fujian Construction Technology, (06),2019,pp.15-20.

3. Qu, C. Z., Liu, L. P.,"Seismic performance analysis of beam column joints of portal frame ". Journal of Northeast Electric Power University, 38 (02), 2018,pp.71-77.

4. Li, J. J., Liu, Z. H., "Study on strengthening the joint stiffness of portal frame ". Building Structure, 48 (04),2018,pp.61-63.

5. Mojtabaei, S. M., Becque, J., Hajirasouliha, I., "Behaviour and Design of Cold-Formed Steel Bolted Portal Frame Connections". ce/papers, 4(2-4) ,2021, pp.432-437.

6. Skejic, D.,"Behaviour of Steel Tube Knee Joint Inserts used in Aluminium Portal Frames". ce/papers, 4(2-4),2021, pp. 174-181.

7. M. Rezaiee-Pajand., Amir, R. M .,"Stability Analysis of Frame Having FG Tapered Beam-Column". International Journal of Steel Structures, 19(2),2019, pp.446-468.

8. Davies, J. M., Roberts, M. J., Wang, Y. C., "Stressed skin theory and structure cladding interaction Safety concerns with Big Sheds". Thin-Walled Structures, 169, 2021,pp. 278-296.

9. Molkens, T., Rossi, B., "Linear elastic mode-based reliability approach for single-bay portal frames". Structures, 34 , 2021, pp.2205-2217.

10. Andrea, B., Simone, L.,"Displacement-based design of precast hinged portal frames with additional dissipating devices at beam-tocolumn joints". Bulletin of Earthquake Engineering, 29, 2021, pp. 1-30.

11. Yurchenko ,V.V., Peleshko ,I. D., Biliaiev, N.,"Application of improved gradient projection method to parametric optimization of steel lattice portal frame". In: 8th International Scientific
Conference "Actual Problems of Engineering Mechanics" Odesa , Ukraine: APEM, 2021,pp.132-145.

12. Aria, G. Jafar, A. M., Mohammad,S.R. "Improving seismic performance of portal frame structures with steel curved dampers". Structures,24(C) ,2020, pp.27-40.

13. Sina, H. M.,Amir,R. M., "Elastoplastic nonlinear behavior of planar steel gabled frame”. Sina Heyrani Moghaddam, 4(4) ,2019, pp.397413.

14. Chen,R.S., Zhang, K., Shi, T., Zhou, F.Z., Chen, J .,"Static load test and finite element analysis of portal frame strengthened with cable support". Journal of Zhejiang University of technology,48 (03),2020,pp.283-289.

15. Wu,Q.B." "Stress analysis and reinforcement effect of end anchor joints strengthened by portal frames".Master thesis of Yanshan University, China, 2020.

16. Liu,T.,"Application effect analysis of portal frame structure in reinforcement of a traction landslide". Construction Technology,49 (13),2020,pp. 118-121

17. Cai,S.X.,"Experimental study on seismic performance of honeycomb beam column portal frame with circular hole and variable section". Master thesis of Shenyang Jianzhu University, China, 2020.

18. Li, G. S., "Connection between wind resistant column of portal frame and lower flange of steel beam and its improvement". Building Structure, 51 (09),2021, pp.128-135.

19. Zhao,G .Q, Ni, K., Wang, Q.H., Guo, J.P., "Steel bonded reinforced portal frame Study on anchorage method of beam column joints ". Engineering Earthquake Resistance and Reinforcement, 43 (02), 2021, pp.130-136.

20. Zhao,G.Q., He, Y.X., Wang,Q.H., Guo, J.P., "Study on mechanical performance of anchorage measures of steel bonded reinforced portal frame columns".Engineering Earthquake Resistance and Reinforcement Transformation, 42 (04),2020, pp.25-30 + 165 . 